\title{
Influence of shrinkage-reducing admixtures on plastic and long-term shrinkage
}

\author{
J. Saliba, E. Rozière, F. Grondin, A. Loukili* \\ Institut de Recherche en Génie Civil et Mécanique (GeM), UMR-CNRS 6183, Centrale Nantes, BP 92101, 44321 Nantes, Cedex 3, France
}

\begin{abstract}
The use of shrinkage-reducing admixtures (SRA) has been suggested to improve concrete performance in terms of lower risk of cracking related to drying shrinkage. Various forms of SRA are commercially available and they may act through different mechanisms. Some SRA mainly acts on drying and weight loss leading to shrinkage.

In this paper, the influence of a liquid SRA on plastic shrinkage, long-term shrinkage, mechanical characteristics as well as concrete pore structure were investigated. Samples of concrete were prepared with two water-to-cement ratios $(w / c)$ to design ordinary and high strength concrete. The effect of the shrinkage-reducing admixture was studied by adding $1 \%$ to the total mass of binder, while keeping the other parameters constant.

At early age, the results indicate that the SRA lead to the same plastic shrinkage for $w / c=0.65$ while it reduced the plastic shrinkage by $25 \%$ for $w / c=0.43$. Drying shrinkage was assessed from 1 day on hardened concrete. The SRA reduced the 7 day drying shrinkage for $w / c=0.65$ and $w / c=0.43$ concrete mixtures by up to $56 \%-31 \%$, respectively, and the 70 day drying shrinkage by up to $33 \%-25 \%$ when the specimens were cured for $24 \mathrm{~h}$ then stored at relative humidity of $50 \%$. At equal water-to-cement ratios, the SRA is seen to be more efficient in reducing drying shrinkage at early ages. These findings suggest that the SRA is most effective when internal relative humidity is relatively high or when higher porosity exists in the material. In fact, the SRA modified the pore structure increasing the total porosity and eliminating the percentage of larger pores with diameters ranging from 300 to $1000 \mathrm{~nm}$. When concerned with drying of concrete, the larger pores are the first ones to lose their internal water and consequently change the RH levels where capillary stresses are the main cause of shrinkage. Thus, this phenomenon may contribute in the reduction of drying shrinkage that occurs when this liquid SRA is used in concrete.
\end{abstract}

\section{Introduction}

Concrete volume change is an unavoidable phenomenon, from very early age to long-term behaviour. Therefore, concrete structures are vulnerable to self stresses or shrinkage cracking which might not only cause serious structural defects but may reduce the serviceability, durability, and aesthetics of concrete structure.

Cracking of concrete is likely to occur in different conditions $[1,2]$, and shrinkage develops through various mechanisms. During the first few hours concrete is still in a semi-fluid or plastic state, from where the term plastic shrinkage [3-7]. At this stage, cementitious materials go through negative volumetric variations, due to chemical origins linked to the hydration of the cement. Then, as water is lost to evaporation (drying shrinkage) or internal reactions (autogenous shrinkage), the menisci present at the interfaces between the water-filled and empty pores will result in the development of stresses within the liquid phase which will also result in

\footnotetext{
* Corresponding author. Tel.: +33 240371667; fax: +33 240372535

E-mail address: ahmed.loukili@ec-nantes.fr (A. Loukili).
}

autogenous stresses and strains within the solid framework of the hydrating cement paste. These stresses pull the cement paste closer together which leads to a volume reduction. Therefore mix constituents such as density, chemical composition, water-tocementitious material ratio, type and size of aggregate, aggregate content, as well as environmental parameters, such as temperature, wind speed and relative humidity, can largely affect the rate of plastic shrinkage [8-14]. If the tensile strength is lower then the stress level caused by restrained to movement, plastic shrinkage cracking occurs $[15,2,16]$. Early age shrinkage is critical since the concrete has the lowest strain capacity and the tensile strength, Young's modulus, and the fracture energy of early age concrete increase slowly during the first hours [17].

Long-term shrinkage often refers to the shrinkage of hardened concrete, typically from $24 \mathrm{~h}$. The autogenous shrinkage component, being mainly dependent on the composition of concrete, develops more rapidly with time than the drying shrinkage. Drying shrinkage depends on the age at beginning of drying and external parameters such as relative humidity and specimen size. In structural members, it may take several months or years to develop and cause cracking. 
Different techniques have been developed to prevent shrinkage from early age. In order to avoid excessive water loss of the surface, immersing it later with water, or covering the surface with wet absorbent materials or even the use of curing compound which form an impermeable film preventing the evaporation of moisture [18] and finally the use of self curing agents which increase the water retention capacity of the concrete $[19,20]$ are often prescribed. Another solution to prevent this cracking is to add a chemical additive to the water-to-cement mixture that can limit shrinkage. Shrinkage-reducing admixtures (SRA) have taken a great interest from researches due to its effect on reducing shrinkage strain which has important benefits from the point of view of the lower risk of restrained shrinkage cracking [21-24]. The SRA used in this research was a non-expansive liquid which was made commercially available after this study.

As various parameters are involved in shrinkage cracking, SRA are likely to act through various mechanisms. The experimental program has been designed to assess the main properties involved in these mechanisms. Thus, this paper deals with a comprehensive study from early age to the hardened state, from microstructure to the material scale to illustrate the impact of the SRA on the behaviour of concrete cured under sealed and drying conditions. The influence of the SRA on the early-age properties including setting, temperature development, and shrinkage properties of concrete has been investigated. The development of mechanical properties of hardened concrete, compressive strength, autogenous shrinkage, unrestrained drying shrinkage, mercury porosimetry and restrained shrinkage cracking potential will be presented. The research results provide a better understanding of the shrinkage mechanism of concrete containing the SRA and offer an effective approach to controlling plastic shrinkage cracks, as it has a significant effect in reducing drying shrinkage.

\section{Experimental program}

\subsection{Materials used}

Four mixtures were investigated. Table 1 summarizes the mixtures proportions, the fresh concrete properties and the constituents for the various mixtures. Concrete mixtures were studied with a water-to-cement ratio $(w / c)$ of 0.65 and 0.43 ; and 0 to $1 \%$ of the SRA content by mass of binder (cement + limestone filler). The SRA was added while maintaining a constant $w / c$ ratio. The SRA mixtures were derived from the base mixture by adding $1 \%$ of the SRA while using the same constituents and keeping all the other parameters constant. All mixture in this study maintained a constant aggregate volume [25] as the gravel-to-sand ratio is equal to 1.02 .

Table 1

Proportions, constituents and properties of concrete mixtures.

\begin{tabular}{lllll}
\hline & C43 & C43SRA & C65 & C65SRA \\
\hline Gravel (rolled gravel $4 / 12)\left(\mathrm{kg} / \mathrm{m}^{3}\right)$ & 836 & 833 & 836 & 833 \\
Sand (river sand 0/4) $\left(\mathrm{kg} / \mathrm{m}^{3}\right)$ & 824 & 821 & 824 & 821 \\
Cement (CEM I 52.5) $\left(\mathrm{kg} / \mathrm{m}^{3}\right)$ & 383 & 383 & 283 & 283 \\
Filler (limestone) $\left(\mathrm{kg} / \mathrm{m}^{3}\right)$ & 163 & 163 & 192 & 192 \\
Water $\left(\mathrm{kg} / \mathrm{m}^{3}\right)$ & 165 & 165 & 185 & 185 \\
Superplasticizers $\left(\mathrm{kg} / \mathrm{m}^{3}\right)$ & 13.7 & 13.7 & 3.5 & 3.5 \\
SRA $\left(\mathrm{kg} / \mathrm{m}^{3}\right)$ & 0 & 5.5 & 0 & 4.8 \\
$w / c$ & 0.43 & 0.43 & 0.65 & 0.65 \\
$w /(c+A)$ & 0.3 & 0.3 & 0.39 & 0.39 \\
Sp $/(c+A)(\%)$ & 1.77 & 1.78 & 0.79 & 0.74 \\
SRA $/(c+A)(\%)$ & 0 & 1 & 0 & 1 \\
Slump flow $(\mathrm{mm})$ & & & 650 & 680 \\
\hline
\end{tabular}

\subsection{Experimental methods}

\subsubsection{Early age testing}

2.2.1.1. Plastic shrinkage. The specimen setup for plastic shrinkage measurement consists of a steel mould $(A)$ of inner size $70 \times 70 \times 280 \mathrm{~mm}^{3}$ whose internal sides are covered by Teflon (Fig. 1). Concrete is cast in an envelope (B) formed by two PVC plates $(C)$, called reflecting plates, attached to a plastic sheet and positioned in the mould; this later is powdered with talc in order to limit friction. The temperature is controlled at $20^{\circ} \mathrm{C}$ by a water circulation in the sides and the bottom of the steel mould. Two laser sensors $(D)$ are used to measure the displacement of the plates dragged along by the concrete while shrinking [26]. Thus the horizontal deformation, that is, plastic shrinkage is calculated.

Tests are performed in an air-conditioned room with a temperature of $20 \pm 1{ }^{\circ} \mathrm{C}$ and relative humidity (RH) of $50 \pm 5 \%$. Free plastic shrinkage tests are realised in the following environmental condition:

(1) Sealed condition: the top surface of the specimen is covered by a plastic sheet to prevent drying. Measured shrinkage is an autogenous shrinkage that is only caused by cement hydration.

(2) No-wind condition: the top surface is allowed to dry in the room. Shrinkage is caused by both drying and hydration.

In addition to horizontal shrinkage, different parameters of significant variation, such as plastic shrinkage, temperature, weight loss, setting time and capillary pressure, were measured in parallel for a better comprehension of shrinkage phenomenon. To determine the evolution of temperature rise due to the hydration reaction, thermocouples, connected to a data-logger that recorded the temperature, were inserted into the middle of the samples immediately after casting.

Tests started 30 min after adding water in the mixing process. All data were logged on a computer at $10 \mathrm{~min}$ intervals for a period of $24 \mathrm{~h}$.

2.2.1.2. Capillary pressure. The main driving force of plastic shrinkage is the build up of hydraulic pressure in the liquid phase of the material, generated by menisci at the surface of concrete (due to desiccation) or inside (due to self-desiccation) [4,5,27-29]. Thus, capillary pressure was measured with the test setup described in Fig. 2 incorporated after the work of Radocea (1992). Two porous ceramic cups were connected to pressure sensors through thin water pipes and placed horizontally in a mould of $70 \mathrm{~mm}$ high and $100 \mathrm{~mm}$ diameter, located at $35 \mathrm{~mm}$ below the concrete top surface.

Water loss was monitored for all the mixtures. After casting, samples are weighed and evaporation was measured in terms of weight loss of a sample $70 \mathrm{~mm}$ high.

2.2.1.3. Setting time. Initial and final setting time was determined for each mixture by an automatic penetration test, the Vicat needle apparatus in accordance with European Standard EN196-3. The setting time is indicated by rapidly increasing penetration resistance. The penetration tests were carried out with water cured sample; moulds were placed in a box containing water of regular temperature of $20^{\circ} \mathrm{C}$ to avoid the undesired effect of dry skin formation.

2.2.1.4. Restrained plastic shrinkage. The restrained plastic shrinkage test used was derived from the procedure followed by Soroushian and Ravanbakhsh [30]. The device consists of a $70 \times 200 \times$ $400 \mathrm{~mm}^{3}$ mould with three stress risers used to provide restraint and promote cracking (Fig. 3). Cracking is created above the central 

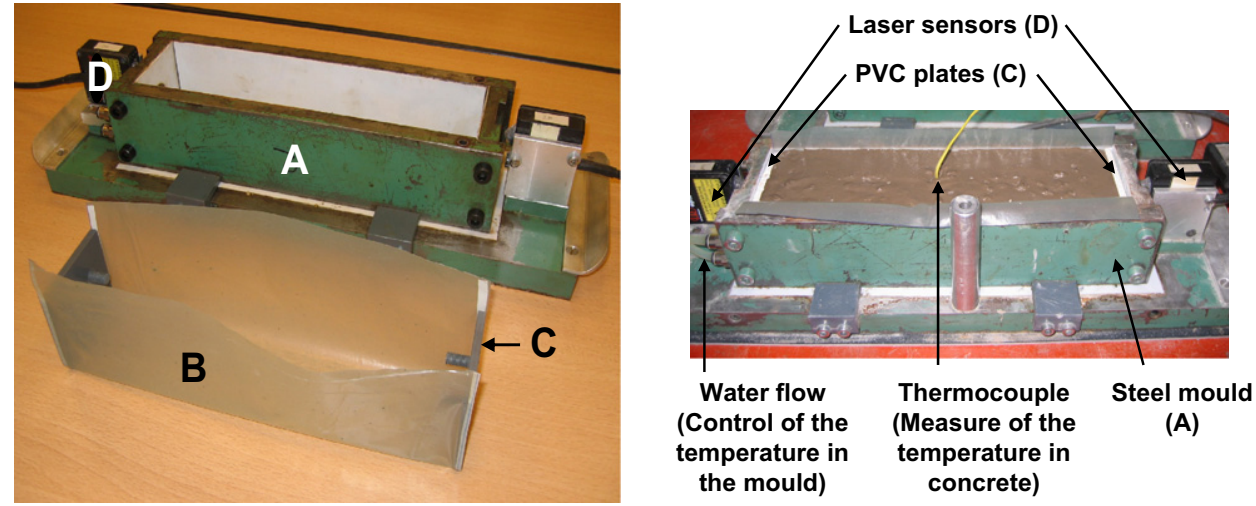

Fig. 1. Plastic shrinkage measurement device with temperature regulation.

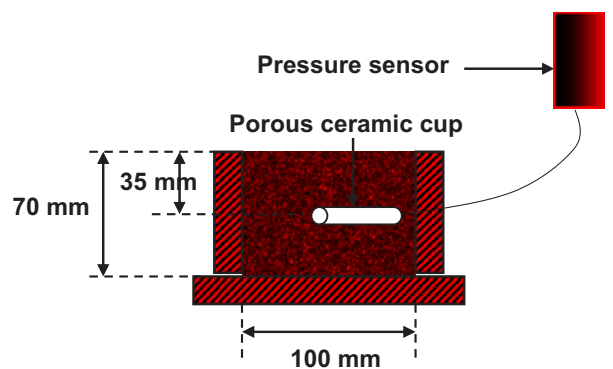

Fig. 2. Schematic section view of setup for measurement of pore water pressure.

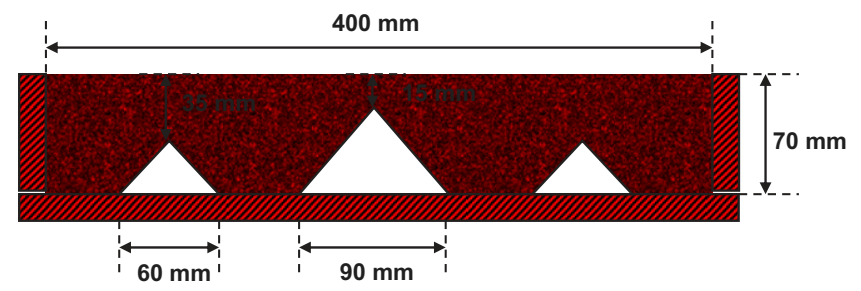

Fig. 3. Schematic section view of restrained shrinkage device.

riser through the depth and across the width of the slab. During testing, the time at which the concrete surface starts cracking is recorded.

Restrained plastic shrinkage tests are done in the wind condition: a fan producing a wind speed of $5 \mathrm{~m} / \mathrm{s}$ is placed next to the specimen to accelerate evaporation rate. In fact, this kind of passive device can produce cracking only in severe drying conditions, that is to say, when wind is applied.

\subsubsection{Properties of hardened concrete}

2.2.2.1. Compressive strength and elastic modulus. Cylindrical specimens of $110 \mathrm{~mm}$ nominal diameter and $220 \mathrm{~mm}$ nominal length were prepared. The compressive strengths of the specimens were measured after $1,7,28,90$ days. These specimens were stored at $20{ }^{\circ} \mathrm{C}$ and $\mathrm{RH}$ of $100 \%$ and were subsequently removed from the moulds on the day of the strength test.

The Grindosonic, a non-destructive method, was used to measure continually the frequency of vibration of the specimen and thus the elastic modulus $E$ was deduced by using the program Emod with the Spinner and Teft model [31].

2.2.2.2. Unrestrained shrinkage. Prismatic specimens $70 \times 70 \times$ $280 \mathrm{~mm}^{3}$ were prepared with and without SRA to measure drying shrinkage. After casting, specimens were covered with a thin sheet of plastic to prevent water loss and maintained at $20^{\circ} \mathrm{C}$ and $\mathrm{RH}$ of $100 \%$ during $24 \mathrm{~h} \mathrm{[32].} \mathrm{Then} \mathrm{the} \mathrm{specimens} \mathrm{were} \mathrm{demolded} \mathrm{and}$ measurements began at the age of $24 \mathrm{~h}$ under the curing conditions of $20 \pm 1{ }^{\circ} \mathrm{C}$ and $\mathrm{RH}$ of $50 \pm 5 \%$. Drying shrinkage specimens were allowed to dry on lateral sides. Autogenous shrinkage was measured on the same prisms; sealed specimens were wrapped with two layers of an adhesive aluminium tape from all side in order to eliminate evaporation.

Shrinkage of hardened concrete was measured with a device equipped with LVDT sensors, which allows following the length of the specimen and recorded it every hour. Weight loss was simultaneously measured in parallel.

2.2.2.3. Restrained shrinkage cracking tendency. One of the widely used devices to restrain concrete shrinkage is metallic rings. A concrete ring is cast around a steel ring. Because steel is stiffer than concrete, volume change of concrete is prevented to a certain extent, which depends on rings dimensions. In this study, the depth of the concrete and steel rings was $70 \mathrm{~mm}$. The inner radius of the steel ring $\left(R_{0}\right)$ was $85 \mathrm{~mm}$, while its outer radius and inner radius of the concrete ring $\left(R_{1}\right)$ was $110 \mathrm{~mm}$. The outer of the concrete ring $\left(R_{2}\right)$ was $180 \mathrm{~mm}$ (so, its thickness was $70 \mathrm{~mm}$ ). The outer circumference of the concrete ring was covered by an aluminium foil to prevent moisture exchange: only the top and bottom surface could dry at temperature of $20^{\circ} \mathrm{C}$ and $\mathrm{RH}$ of $50 \%$.

Note that after casting, specimens were covered with a thin sheet of plastic to prevent water loss and maintained at $20^{\circ} \mathrm{C}$ and $\mathrm{RH}$ of $100 \%$ during $24 \mathrm{~h}$ before the beginning of measurements.

Shrinkage cracking potential was defined as the relative time at which the concrete ring cracked. In order to increase the potential of cracking at early age, a $20 \mathrm{~mm}$ notch was placed on the outer circumference of the steel ring. Moreover, four strain gages were placed on the inner circumference of the steel ring. This measurement provides information on the stress state in the concrete.

2.2.2.4. Mercury intrusion porosimetry. The effect of the SRA on pore size distribution was evaluated using high-pressure mercury intrusion porosimeter. These parameters were determined on concrete after 54 days; the specimens were cut into small pieces from the centre and the edge, for mixture with and without the SRA. In this test, pressure was used to press nonwetting liquid mercury into the pores in concrete. The pressure in the porosimeter was slowly increased from 0.5 to 60,000 psi. The amount of pressure needed to force the mercury into pores of certain sizes is inversely proportional to the pore size. The measurements were recorded and used to draw the pore volume against the pore radius. 


\section{Results and discussion}

\subsection{Early age behaviour}

In sealed conditions, Fig. 4 shows approximately the same amount of autogenous shrinkage with and without the SRA for $w / c=0.43$ and similar results were obtained with $w / c=0.65$. Thus SRA had no important effect on autogenous shrinkage at early age.

Since the surface of concrete is subjected to drying conditions, C65 and C65SRA mixtures had about the same behaviour and the difference of shrinkage is not significant. However, the plastic shrinkage is reduced by $25 \%$ when the SRA is added to C43 admixture.

The analysis of the plastic shrinkage curves revealed four phases (Fig. 5):

\subsubsection{First phase}

No significant horizontal shrinkage was observed. The concrete volume change was mainly caused by plastic settlement due to the effect of gravity and chemical shrinkage. This consolidation leads to an increase of packing density of concrete, which forces water to percolate to the top surface. As a result, bleeding may occur during this phase. In this phase, immediately after placing the specimens in the environmental chamber, all concrete had a similar rate of evaporation and therefore the initial temperature drop during the first minutes of drying to the wet-bulb temperature was identical.

\subsubsection{Second phase}

Horizontal deformation began to appear. As shown by Radocea, capillary forces are not large enough to create horizontal deformation. Shrinkage means also that the concrete internal friction angle

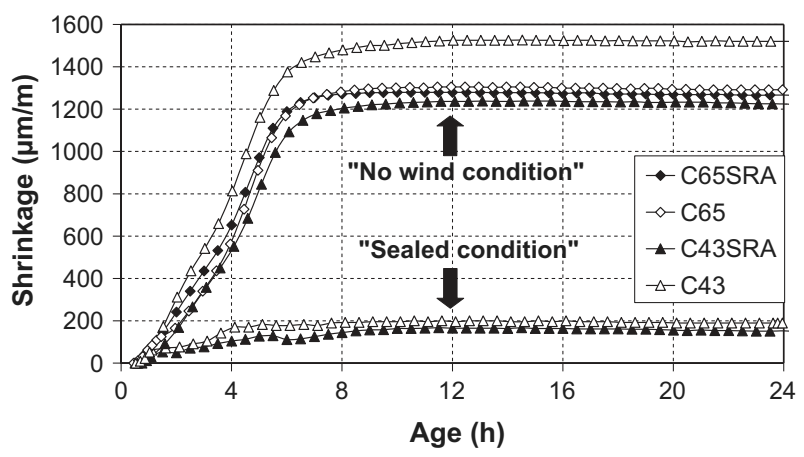

Fig. 4. Development of plastic shrinkage vs. time for mixtures with and without SRA.

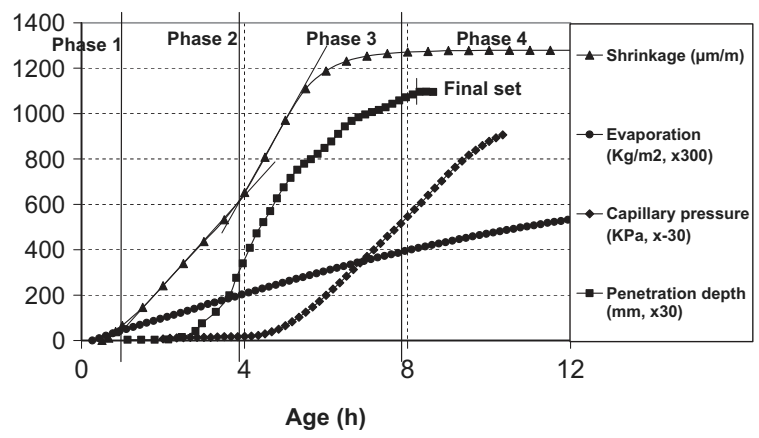

Fig. 5. Development of plastic shrinkage, evaporation, capillary pressure and setting time for C65SRA admixture. is adequately high and particles interact [10]. Granular interactions are gradually favored by consolidation, increase of solids volume (hydration) and decrease of water content (consolidation, hydration, evaporation). Thus volumetric contractions are little by little transmitted horizontally. Mixture with the SRA showed a higher fluidity with slump test and a delay in initial setting time (Fig. 6.) and therefore decreases the internal friction angle which could explain the decrease in the shrinkage development for SRA mixtures. The menisci remains at the outer surface of the concrete and no pores inside the body are emptied. The development of capillary pressure was not very important during this stage; the mixture still fluid enough, small capillary pressure would induce shrinkage and a direct displacement of the particles (Fig. 7). Fig. 8 shows loss weight of concrete with and without the SRA

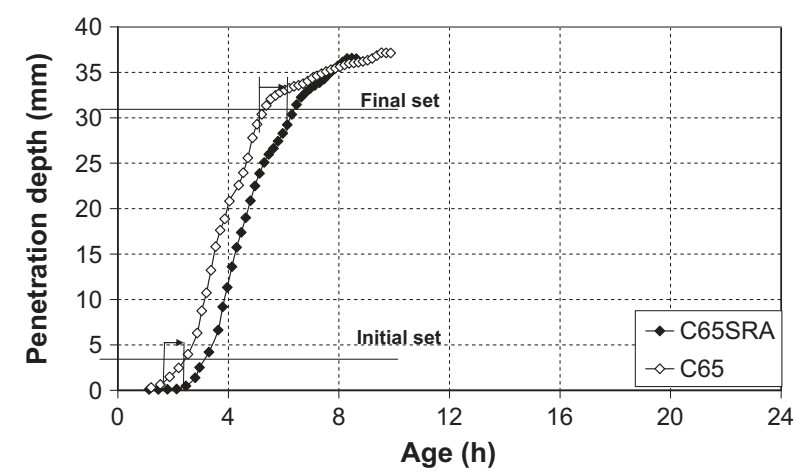

Fig. 6. Experimentally measured initial and final set times.

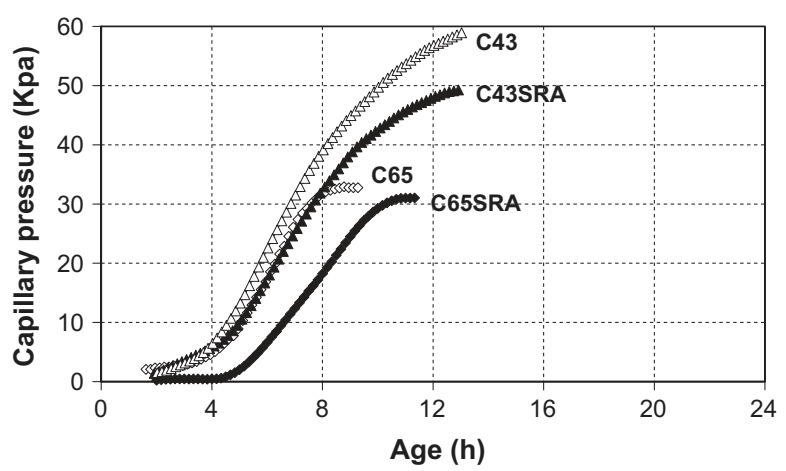

Fig. 7. Influence of $w / c$ ratio and SRA on the development of pore water pressure at $35 \mathrm{~mm}$ depth of concrete.

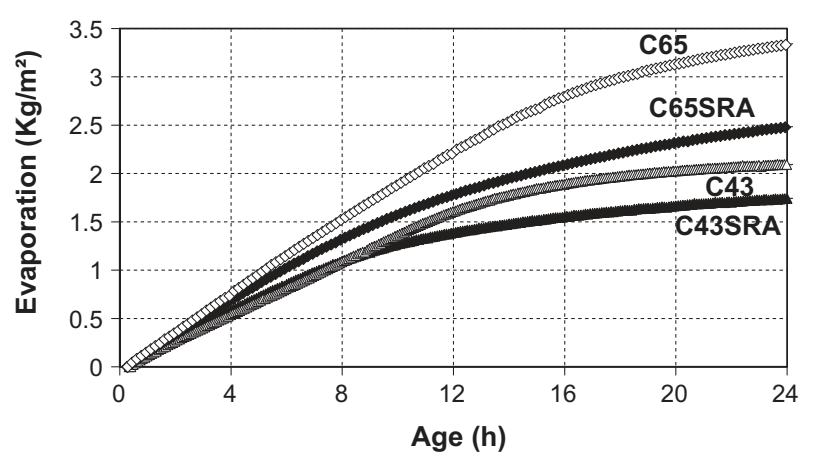

Fig. 8. Influence of $w / c$ ratio and SRA on the specific mass change during evaporation. 
divided by the surface area of the specimen. It can be observed that the evaporation rate is almost constant and the addition of 1\% SRA has a little influence on the evaporation rate of water during this stage. Therefore, any change in deformation rate is only caused by changes in concrete microstructure.

Note that the rate of evaporation was higher in $w / c=0.65 \mathrm{mix}-$ ture than 0.43 . A high $w / c$ generally has a large number of interconnected capillary voids that allows water to easily rise or bleed. Therefore at a given time period more water can rise up in the sample and weight loss of the sample is high [16].

\subsubsection{Third period}

Once the layer of bleeding water at the surface is consumed by evaporation, air-liquid menisci are formed in the liquid between the solid particles on the surface. We observed that water pressure decreased slightly and horizontal deformation began to appear. The studied mixtures actually had few bleeding water, since C65 mixtures are self-consolidating concrete (SCC) mixtures and C43 are derivative mixtures with a lower $w / c$ ratio. Shrinkage of the concrete under the effect of capillary pressure is resisted in part by the elastic modulus of the solid network and by the friction between the pore fluid and the network. As evaporation proceeds, both permeability and compressibility are reduced and the magnitude of the pressure gradient increases. Starting at approximately $4 \mathrm{~h}$, the development of capillary pressure takes an exponential function and concrete shows a decrease in capillary pressure. Moreover because the capillary pressure is lower in the concrete with $1 \%$ SRA (Fig. 7), the decrease of the evaporation rate appeared earlier for SRA mixtures (Fig. 8).

In concrete with the SRA, the rate of evaporation is lower than that of the plain concrete after the first hours of drying. The amount of water loss is also related to the bleeding behaviour of the specimen, which in turn depends on concrete pore structure. The higher percentage of water loss for base mixture with both $w / c$ ratios may be explained by larger pores in the structure at the very early age stage, while SRA mixtures present a better distribution of the porous system. The high percentage of larger pore in the paste and consequently a high bleed rate cause a high weight loss [16]. These differences concerning lower evaporation and lower development of capillary pressure induce a lower development of plastic shrinkage which results in lower consolidation.

As the cement hydrates, hydration products, that bonds all loose aggregate particles together, form around the cement particles. Capillary pressure produced by the menisci on the surface consolidates the concrete solid skeleton as the tension in the fluid serves to bring the particles closer to each other. As a consequence, this period presents a progressive slowing down of the plastic shrinkage due to the stiffness of the solid skeleton.

At the end of this stage, the horizontal deformation of the concrete is increasingly hindered because the capillary pressure is no longer able to compress the solid skeleton and force water to the surface. At this point the radius of the liquid-air menisci decreases until a break-through radius and the front water is shifted towards the inner part of the specimen.

Typical examples of the temperature evolution in concrete with and without the SRA illustrates that the temperature starts to rise gradually in the plain concrete at approximately $4 \mathrm{~h}$ due to the contribution of the heat of hydration while the temperature rise occurred later in the mixture containing the SRA. This observation show a good correlation with the time of final set and the peak of hydration. After reaching the peak, the temperature gradually decreases to the ambient temperature.

Fig. 9 shows only the temperature that was measured in $w /$ $c=0.65$ mixtures at autogenous condition, however similar results were obtained in drying condition for both $w / c$ ratios. It is also interesting to note that the temperature gradient of the specimens

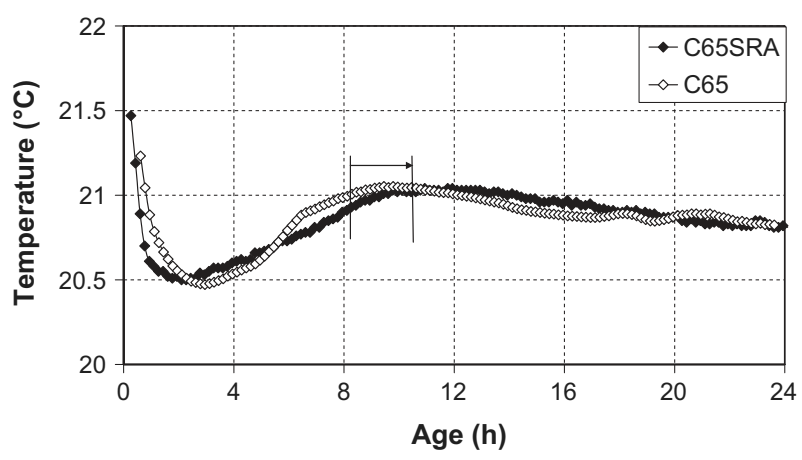

Fig. 9. Typical temperature measurements for specimens with and without SRA.

was not very significant. Consequently, the deformation due to the thermal gradient can be neglected and there is no coupling between shrinkage and temperature [33].

\subsubsection{Fourth phase}

This stage corresponds to a shrinkage limit; the granular media has been packed so that it is then dense enough to resist the capillary pressure. Volumetric contraction stops and the shrinkage curve flattens.

The evaporation rate reduces further because the menisci enter the specimen. Water is drawn from the inside of the specimen and a continuous liquid path between surface and interior is lost.

Fig. 10 shows the results of the restrained shrinkage tests performed in the wind condition. SRA mixtures tended to crack later. Moreover the crack width of the SRA mixtures was smaller than the crack width of the base mixtures. This result seems to be consistent with the capillary pressure measurements as SRA mixtures had the slowest capillary pressure development.

\subsection{Compressive strength}

The development of compressive strength is given in Fig. 11. In each case, three replicates were tested for each mixture and curing age. For concrete mixtures with $w / c=0.65$ (C65 and C65SRA), we observed a $4 \%-7 \%$ reduction in strength for specimens with the SRA, and a reduction of $8 \%-14 \%$ measured for $w / c=0.43$ mixture (C43SRA), respectively. Compressive strength diminishes slightly in concrete with both $w / c$ ratios when concrete mixtures were designed with the SRA [34]. This diminution could be due to the fact that the SRA leads to an increase of average pore diameter (Fig. 17), and consequently to a decrease of the mechanical strength observed. The effect of the SRA was much more effective in reducing

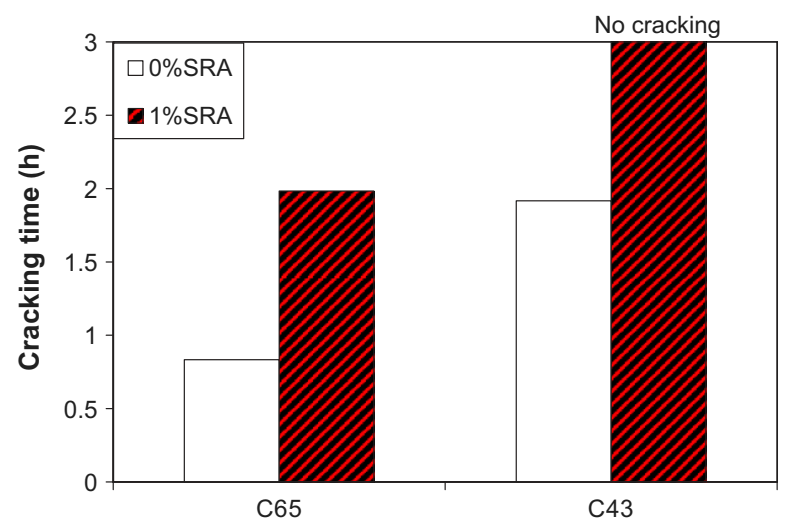

Fig. 10. Cracking time for concretes with and without SRA. 


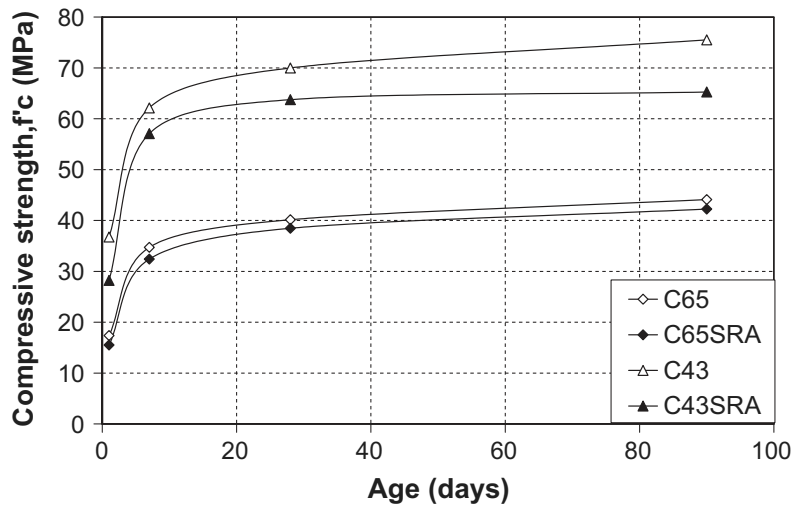

Fig. 11. Evolution of the compressive strength of studied concretes.

plastic shrinkage for $w / c=0.43$ mixture, consequently less consolidation of the solid skeleton and therefore higher porosity; which could explain the difference of the resistance loss between both $w / c$ ratios mixture. The measurements of the elastic modulus had the same tendency of compression strength tests and SRA diminishes slightly this later. In fact, the modulus of elasticity increased rapidly during the first days to attend constant values of $45.2 \mathrm{GPa}$ for C65SRA mixture and $48.1 \mathrm{GPa}$ for C65 base mixture with $w /$ $c=0.65$, respectively 49.8 and 49.9 with $w / c=0.43$.

\subsection{Long-term shrinkage}

\subsubsection{Drying shrinkage}

At long term, volumetric changes occur in concrete for several reasons including temperature fluctuations, self-desiccation (internal drying), or loss of water from the capillary pores and the gel (external drying). Moreover, the reduction in the relative humidity in the pore system causes a water-air meniscus that subjects the pore walls to considerable stress. The resulting increase in the stress on the porous structure leads to substantial self-drying shrinkage. The overall shrinkage is therefore represented as the sum of the thermal, drying, and autogenous shrinkage. In this work, the specimens were maintained at a constant temperature environment of $20^{\circ} \mathrm{C}$ after mixing, implying that temperature changes occur only as a result of hydration. After $24 \mathrm{~h}$, the variation of temperature in the studied mixture was small so this effect can be neglected.

Total shrinkage of concrete specimens for both $w / c$ ratios, with and without the SRA, subjected to desiccation is shown in Fig. 12.

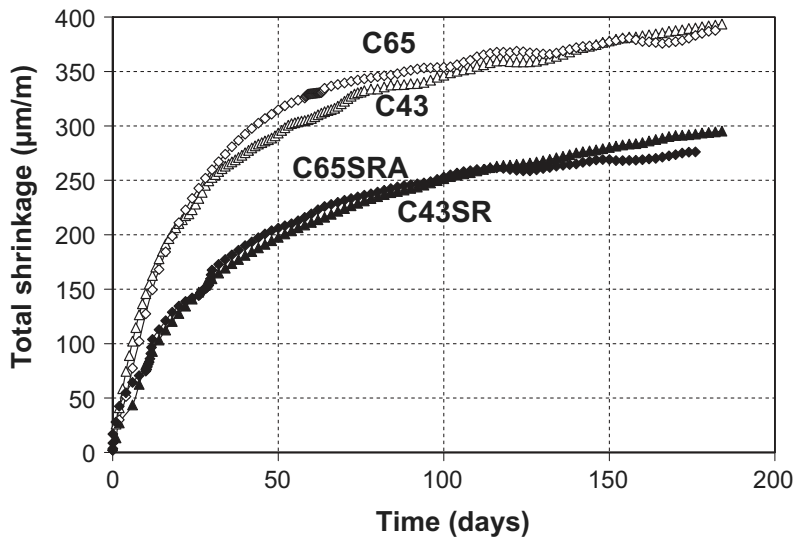

Fig. 12. Influence of $w / c$ ratio and SRA on the total long-term shrinkage (drying initiated at $24 \mathrm{~h}$ ).
In the presence of the SRA there is a significant reduction with respect to the reference concrete in the drying shrinkage. The addition of $1 \%$ SRA reduced the shrinkage by up to $56 \%$ at 7 days and $33 \%$ at 70 days for $w / c=0.65$ mixtures, and $31 \%-25 \%$ for $w /$ $c=0.43$ mixtures respectively. The reduction in the drying shrinkage appears to be relatively consistent and independent of the water cement ratio. It can be seen that the SRA mixture demonstrated very low shrinkage rate during the initial few days and was much more effective in reducing shrinkage at early ages. These findings suggest that the SRA is more effective when the internal relative humidity is relatively high or when a higher porosity exists in the material.

The beneficial effect of the SRA is due primarily to two developments: first, the redistribution of the porous structure while decreasing the percentage of larger pores; in this case, the percentage of pores with diameters ranging from 0.3 to $1 \mu \mathrm{m}$, was lower in concrete with the SRA (Fig. 17). As the kinetics of evaporation are higher in larger pores, the larger capillary pores empty whereas the menisci in smaller pore remain at the surface. Therefore the loss of water diminishes and consequently causes smaller internal stress when the water evaporates. Secondly the SRA increased the total porosity, which may be due to a delayed hydration reaction that can be observed in SRA mixtures. Thus, higher retention of water and consequently higher RH which exhibit a lower capillary stress that prevails in concrete with the SRA [1].

The $\mathrm{RH}$ is the controlling parameter in specimens exposed to external drying. Therefore, according to the findings, the SRA reduced drying shrinkage in concrete, modifying the pore structure and increasing $\mathrm{RH}$.

The drying shrinkage strain was also computed based on the difference between the sealed and unsealed shrinkage strain. This simplification allows drawing interesting conclusions even if the value of drying shrinkage is not totally exact because the conditions of exchange of humidity with exterior environment had an influence on the hydration. Fig. 13 shows that the effect of the SRA is primary due to desiccation and the SRA was more effective with $w / c=0.65$ than $w / c=0.43$.

\subsubsection{Autogenous shrinkage}

Autogenous shrinkage is the shrinkage that occurs independently of external water loss or temperature change. Concrete undergoes autogenous shrinkage, as a result of two developments, namely: chemical shrinkage and self-drying shrinkage.

The average autogenous shrinkage is provided in Fig. 14. As expected, the mixtures with the lowest $w / c$ had the highest autogenous shrinkage. Autogenous shrinkage of C65 mixture was $69 \mu \mathrm{m} / \mathrm{m}$, while C65SRA mixture had a 90 day autogenous shrinkage of $55 \mu \mathrm{m} / \mathrm{m}$ respectively $137 \mu \mathrm{m} / \mathrm{m}$ and $118 \mu \mathrm{m} / \mathrm{m}$ for C43 and

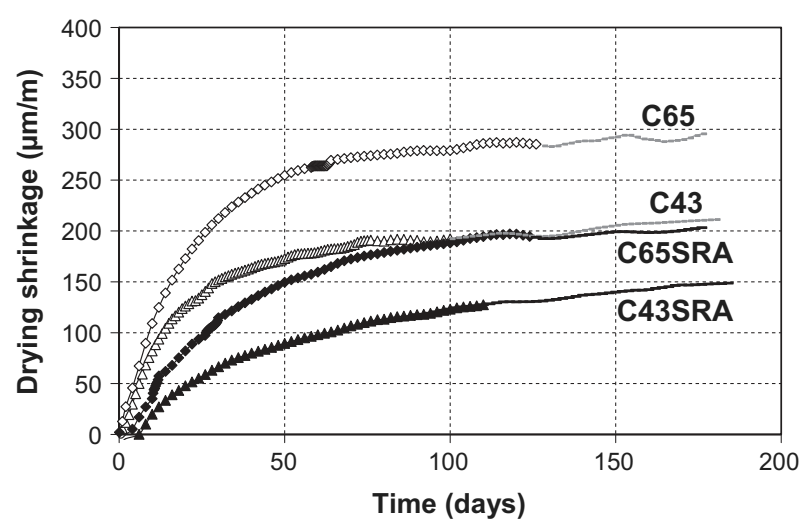

Fig. 13. Influence of $w / c$ ratio and SRA on the drying shrinkage of concretes. 


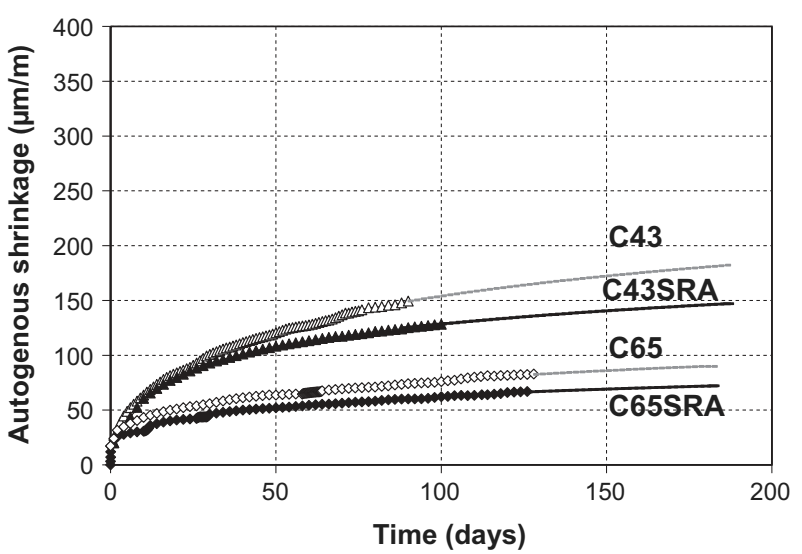

Fig. 14. Influence of $w / c$ ratio and SRA on the autogenous shrinkage: measurements and trend curves.

C43SRA mixtures. When the specimens were in autogenous conditions, the addition of $1 \%$ SRA reduced shrinkage by only $20 \%$ for $w /$ $c=0.65$ while $w / c=0.43$ generated $14 \%$ decline.

The use of the SRA showed a small influence on the early autogenous shrinkage. The relatively small delay in hydration, which would result in a substantial reduction in the degree of hydration, as well as water retention, could explain the relative reduction in self-desiccation and autogenous shrinkage.

However the difference of the effect of the SRA in autogenous and drying condition is due to the fact that the menisci of smaller pores for SRA mixtures may break down earlier and release capillary stresses, therefore reduce shrinkage at lower $\mathrm{RH}[1]$.

\subsubsection{Weight loss}

A typical weight loss due to water evaporation from concrete with and without the SRA, both exposed to the same condition $\left(\mathrm{RH}=50 \%, T=20^{\circ} \mathrm{C}\right)$ was measured. Results show a slightly lower initial weight loss for C65SRA and C43 mixture. It is interesting to note that marginally lower weight loss is typically observed at later ages. Specimens with higher $w / c$ demonstrated a higher weight loss. This is important in that it suggests that mixtures containing the SRA loose a similar amount of water suggesting a change in material behaviour as opposed to a delay in shrinkage.

Drying shrinkage was also plotted vs. the loss of mass, expressed in \% (Fig. 15). Two typical phases can be distinguished on these curves. During the first one, drying does not generate shrinkage. This is likely due to the cracking of the specimen skin [33]. During the second phase, shrinkage increases almost linearly with drying degree. It is interesting to note that SRA concrete showed a

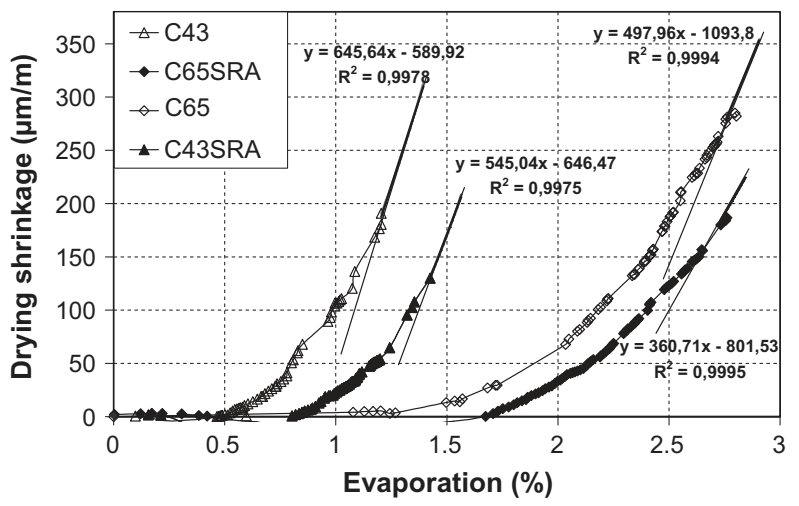

Fig. 15. Drying shrinkage vs. loss of mass for different concretes. higher slope than the reference concrete specimens. Thus, the kinetics of shrinkage is different for SRA mixtures.

\subsubsection{Calculation of the maximum tensile stress and cracking age of concrete ring}

The strain that developed on the inner surface of the steel ring was monitored throughout the test. Fig. 16 illustrates the stress development as measured in specimens with and without the SRA. It can be noticed that up to an age of approximately 40 days C65 and C65SRA concrete specimens exhibited similar behaviour. After this time their behaviour began to diverge. The rate of stress development in the base mixture began to decrease rapidly suggesting that cracking may have caused a relaxation of stresses in C65 concrete and main crack appeared at approximately 80 days. In the C65SRA specimen the rate of stress development does not decrease rapidly presumably due to the fact that they present a lower shrinkage as showed before.

\subsection{Discussion on results from mercury intrusion porosimetry}

The total porosity and average pore diameter of the C65 and C65SRA concrete samples at the centre and at the edge, as well as concrete pore size distribution were measured by mercury intrusion porosimetry.

The pore distribution ( $\mathrm{d} v / \mathrm{d} \log r)$, a derivative of the cumulative pore volume $v$ with respect to the logarithm of the pore radius $r$, is presented vs. the pore radius $r$ (Fig. 17). Both concrete with and without the SRA had the highest derivative value $(\mathrm{d} v / \mathrm{d} \log r)$ at a pore radius of approximately $0.2 \mu \mathrm{m}$ with a slight higher value for the SRA mixture. This indicates that a major group of

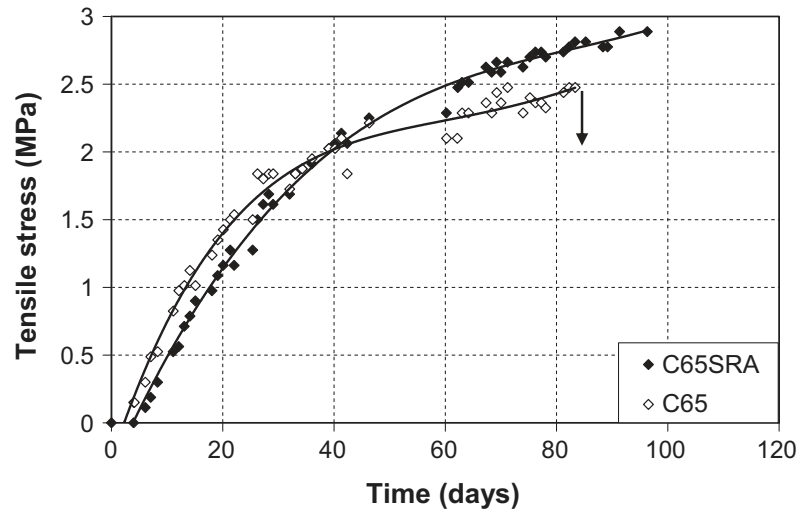

Fig. 16. Stress development in restrained shrinkage for C65 with and without SRA.

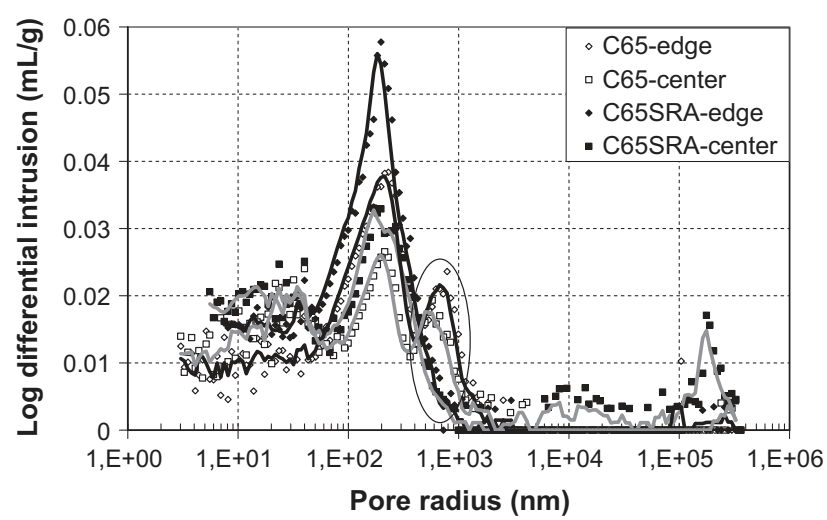

Fig. 17. Effect of SRA on pore size distribution for C65 at 54 days. 
interconnected pores in concrete has this pore size. A slight difference has been also detected between the centre and the edge. However the C65SRA concrete had a lower percentage of pores with sizes ranging from 0.3 to $1 \mu \mathrm{m}$. Consequently the base mixture has a supplementary pore system of larger pore and a second peak of the curve is located at a pore radius of approximately $0.6 \mu \mathrm{m} / \mathrm{m}$. This may be explained by the role of the SRA in increasing the deflocculation of the mixture and consequently a better distribution of pore system. Further, the higher porosity may be the result of a reduction in the rate of cement hydration and consequently a delayed setting and a slower strength development $[35,36]$.

It may be deduced from the data that the total porosity value is larger in specimens containing 1\% SRA, the same tendency was also obtained with water porosimetry. As discussed previously, the paste pore structure influences drying behaviour and also affects pore pressure development in the paste.

\section{Conclusion}

The study presented in this paper provides a comprehensive set of experimental data about the effect of a liquid shrinkage-reducing admixture (SRA) on early age and long-term behaviour of concrete. The influence of boundary conditions (sealed or unsealed) on the effect of the SRA is described. The paper gives consistent analyses to understand how this SRA can help in reducing shrinkage and cracking of low and high water-to-cement $(w / c)$ ratio concrete (0.43 and 0.65$)$. The main conclusions drawn from the study are:

- The rate of evaporation of concrete mixtures with the SRA was lower than that of the plain concrete mixtures after the first hours of drying. The higher percentage of water loss for base mixtures with both $w / c$ ratios may be explained by larger pores in the structure at the very early age stage, while SRA mixtures presented a better distribution of the porous system. The high percentage of larger pores and consequently a high bleeding rate cause a high weight loss. These differences concerning lower evaporation and lower development of capillary pressure results in lower consolidation.

- The addition of $1 \%$ SRA reduced long-term drying shrinkage at 7 days by up to $56 \%$ for $w / c=0.65$ mixture, and $31 \%$ for $w /$ $c=0.43$ mixture respectively. A continuous measurement of the drying shrinkage was done in order to show that the effect of the SRA was not just a delay in the development of the total shrinkage. Results have shown that final shrinkage was actually reduced. The reduction in the drying shrinkage actually appeared to be relatively consistent and independent of the $w / c$ ratio. It should be noted that the SRA mixtures showed very low shrinkage rates during the initial few days. These findings suggest that the SRA is more effective when the internal humidity is relatively high or when a higher porosity exists in the material.

- The percentage of pores with diameters ranging from 0.3 to $1 \mu \mathrm{m}$ was lower in concrete with the SRA. This confirms that the beneficial effect of the SRA is due primarily to the redistribution of the porous structure while decreasing the percentage of larger pores. As the kinetics of evaporation are higher in larger pores, the larger capillary pores empty whereas the menisci in smaller pore remain at the surface. Therefore the loss of water diminishes and consequently causes smaller internal stress when the water evaporates. Moreover the SRA increased the total porosity, which may be due to a delayed hydration reaction that can be observed in SRA mixtures. Thus, higher retention of water and consequently higher relative humidity which exhibit a lower capillary stress that prevails in concrete with SRA.
- The use of the SRA showed a small influence on the early autogenous shrinkage. The relatively small delay in hydration, which would result in a substantial reduction in the degree of hydration, as well as water retention, could explain the relative reduction in self-desiccation and autogenous shrinkage.

- The addition of the SRA caused a slight reduction in the compressive strength and elastic modulus of the concrete mixtures with both $w / c$ ratios. This reduction could be due to an increase of average pore diameter. This may be the result of a reduction in the rate of cement hydration and consequently a delayed setting and a slower strength development. A delay in the development of capillary stress and heat release was actually observed.

- Concrete mixtures with the SRA showed lower time to cracking and opening of cracks, due to plastic shrinkage or long-term drying shrinkage. Reduced early age and long-term shrinkage, and equivalent mechanical properties, could explain this effect.

This study could be extending to a comparative study between others types of SRA, for instance the admixtures for shrinkagecompensating concrete. These admixtures lead to an expansive behaviour for concrete at early age. To study their behaviour, it will be interesting to develop a device to measure the strain, also the stress, resulting of the expansion.

\section{References}

[1] Turcry P. Retrait et fissuration des bétons autoplacants, influence de la formulation, French PhD dissertation, Ecole Centrale de Nantes 2004.

[2] Hannant DJ, Branch J, Mulheron M. Equipment for tensile testing of fresh concrete. Mag Concr Res 1999;51(4):263-7.

[3] Radocea A. A model of plastic shrinkage. Mag Concr Res 1994;46(167): 125-32.

[4] Wittmann FH. On the action of capillary pressure. Cem Concr Res 1976;6(1): 49-56.

[5] Radocea A. Autogenous volume change of concrete at very early age. Mag Concr Res 1998;50(2):107-13.

[6] Barcelo L, Boivin S, Acker P, Toupin J, Clavaud B. Early age shrinkage of concrete: Back to physical mechanisms. Concr Sci Eng 2001;3(10):85-91.

[7] Kronlöf A, Leivo M, Sipari P. Experimental study on the basic phenomena of shrinkage and cracking of fresh mortar. Cem Concr Res 1995;25(8): 1747-54.

[8] AL-Fadhala M, Hover KC. Rapid evaporation from freshly cast concrete and the Gulf environment. Constr Build Mater 2001;15(1):1-7.

[9] Hover KC. Evaporation of water from concrete surfaces. ACI Mater J 2006;103(5):384-9.

[10] Dias WPS. Influence of mix and environment on plastic shrinkage cracking Mag Concr Res 2003;55(4):385-94.

[11] Almusallam AA. Effect of environmental conditions on the properties of fresh and hardened concrete. Cem Concr Compos 2001;23(4-5):353-61.

[12] Wang K, Shah SP, Phuaksuk P. Plastic shrinkage cracking in concrete materialsinfluence of fly ash and fibers. ACI Mater J 2001;98(6):458-64.

[13] Uno PJ. Plastic shrinkage cracking and evaporation formulas. ACI Mater J 1998;95(4):365-75.

[14] Cabrera JG, Cusens AR, Brookes-Wang Y. Effect of superplasticizers on the plastic shrinkage of concrete. Mag Concr Res 1992;44(160):149-55.

[15] Cohen MD, Olek J, Dolch WL. Mechanism of plastic shrinkage cracking in Portland cement and Portland cement-silica fume paste and mortar. Cem Concr Res 1990;20:103-19.

[16] Hammer TA. On the strain capacity and cracking mechanisms of high strength concrete on very early age. Elsevier Science; 2001

[17] Dao VTN, Dux PF, Morris PH. Tensile properties of early-age concrete. AC Mater J 2009;106(6)

[18] Audenaert K, De Schutter G. Towards a fundamental evaluation of water retention tests for curing compounds. Mater Struct 2002;35(August): 408-14.

[19] El-Dieb AS. Self-curing concrete: water retention, hydration and moisture transport. Constr Build Mater 2007;21:1282-7.

[20] Jensen OM, Lura P. Techniques and materials for internal water curing of concrete. Mater Struct 2006;39:817-25.

[21] Weiss J, Lura P, Rajabipour F, Sant G. Performance of shrinkage-reducing admixtures at different humidities and at early ages. ACI Mater J 2008;105(5): 478-86.

[22] Lura P, Pease B, Mazzotta GB, Rajabipour F, Weiss J. Influence of shrinkagereducing admixtures on development of plastic shrinkage cracks. ACI Mater J 2007;104(2):187-94.

[23] Collepardi M, Borsoi A, Collepardi S, Olagot J, Troli R. Effects of shrinkage reducing admixture in shrinkage compensating concrete under non-wet curing conditions. Cem Concr Compos 2005;27:704-8. 
[24] Palacios M, Puertas F. Effect of shrinkage-reducing admixtures on the properties of alkali-activated slag mortars and pastes. Cem Concr Res 2007;37:691-702.

[25] Rozière E, Granger S, Turcry Ph, Loukili A. Influence of paste volume on shrinkage cracking and fracture properties of self-compacting concrete. Cem Concr Compos 2007;29(8):626-36.

[26] Turcry P, Loukili A. Evaluation of plastic shrinkage cracking of selfconsolidating concrete. ACI Mater J 2006;103(4):272-9.

[27] Morris PH, Dux PF. Suction, fracture energy, and plastic cracking of cement mortar and concrete. ACI Mater J 2005;102(6):390-6.

[28] Amziane S, Andriamanantsilavo N. Prediction of cement paste pore water pressure variations during setting period. Adv Cem Res 2004;16(1):23-8.

[29] Slowik V, Schmidt M, Fritzsch R. Capillary pressure in fresh cement-based materials and identification of air entry value. Cem Concr Compos 2008;30: 557-65.

[30] Soroushian P, Ravanbakhsh S. Control of plastic shrinkage cracking with specialty cellulose fibers. ACI Mater J 1998;95(4):429-35.
[31] Spinner S, Tefft WE. A method for determining mechanical resonance frequencies and for calculating elastic moduli from these frequencies. Proc. ASTM 1961:1221-38.

[32] Turcry P, Loukili A, Haidar K, Pijaudier-Cabot G, Belarbi A. Cracking tendency of self-compacting concrete subjected to restrained shrinkage: Experimental study and modelling. J Mater Civ Eng 2006;18(1).

[33] Mounanga P, Baroghel-Bouny V, Loukili A, Khelidj A. Autogenous deformations of cement pastes: Part I. Temperature effects at early age and micro-macro correlations. Cem Concr Res 2006;36(1):110-22.

[34] Bentz DP, Hansen KK, Geiker MR. Shrinkage-reducing admixtures and early age desiccation in cement pastes and mortars. Cem Concr Res 2001;31(7): 1075-85.

[35] Rajabipour F, Sant G, Weiss J. Interactions between shrinkage reducing admixtures (SRA) and cement paste's pore solution. Cem Concr Res 2008;38: 606-15.

[36] Folliard KJ, Berke NS. Properties of high-performance concrete containing shrinkage-reducing admixture. Cem Concr Res 1997;27(9):1357-64. 